\title{
Structural arrangement of collagen fibrils in the periarterial connective tissue of the kidney: their functional relevance as a structural stabilizer against arterial pressure
}

\author{
Yasue Hosoyamada $\cdot$ Tatsuo Sakai
}

Received: 15 August 2011/Accepted: 16 November 2011/Published online: 21 December 2011

(C) The Author(s) 2011. This article is published with open access at Springerlink.com

\begin{abstract}
Periarterial connective tissue with a moderate amount of collagen fibrils is known to be a specialized domain in the renal interstitium. This study aimed to clarify the microscopic architecture of the periarterial connective tissue as a mechanical supportive structure of the intrarenal arteries. Transmission and scanning electron microscopy revealed two populations of collagen fibrils in the periarterial connective tissue. The major one was composed of many bundles of collagen fibrils running in longitudinal directions, whereas the minor one was represented by a few circumferential bundles adjacent to the smooth muscles. The amount of collagen fibrils was obviously variable and correlated with the arterial caliber. The correlation between abundance of collagen fibrils and the arterial caliber was confirmed by morphometric analysis of the collagen fibril area per arterial perimeter on electron micrographs. The size of individual collagen fibrils was measured in periarterial connective tissue of arteries with various calibers. A positive correlation between the diameter of collagen fibrils and arterial caliber was confirmed, indicating the supportive function of collagen fibrils in the periarterial connective tissue. The accumulated morphological findings supported the hypothesis that the collagen fibrils in the periarterial
\end{abstract}

Y. Hosoyamada

Department of Nutrition, Faculty of Health Care Sciences,

Chiba Prefectural University of Health Sciences, Chiba, Japan

Y. Hosoyamada $\cdot$ T. Sakai $(\bowtie)$

Department of Anatomy and Life Structure,

Faculty of Medicine, Juntendo University,

2-1-1 Hongo, Bunkyo-ku, Tokyo 113-8421, Japan

e-mail: tatsuo@juntendo.ac.jp

T. Sakai

Sportology Center, Juntendo University Graduate School

of Medicine, Tokyo, Japan connective tissue develop longitudinal tension with their tensile strength, whereas the smooth muscle cells in the media develop circumferential tension with active regulation of contracting force.

Keywords Artery - Interstitium - Periarterial connective tissue $\cdot$ Collagen fibrils · Kidney

\section{Introduction}

The periarterial connective tissue is a unique domain of the renal interstitium. Lemley and Kriz (1991) distinguished four types of interstitium in the kidney: the peritubular interstitium, periarterial connective tissue, glomerular and extraglomerular mesangium, and medullary interstitium. The periarterial connective tissue surrounds the intrarenal arterial tree up to the glomerular hilum, and contains lymphatic ducts and sympathetic nerve fibers (Kriz and Dieterich 1970; Barajas and Wang 1975). Electron microscopic observations have revealed that the periarterial connective tissue contains moderate amounts of collagen fibrils, whereas the peritubular interstitium possesses a paucity of such fibrils (Kriz and Kaissling 1985).

The tensile strength of collagen fibrils is suitable for the mechanical support of organs in the body. The supportive function of collagen fibrils is well demonstrated by the dense connective tissue of ligaments at the joints, the tendons at the end of muscles, and the dermis of the skin. Recent studies have elucidated that collagen fibrils in the loose connective tissue of the visceral interstitium have a supportive function. Lorber $(1989,1991,1992,1993)$ and Hosoyamada and Sakai (2003) studied the interstitial connective tissue of several exocrine glands, and revealed that the intra- and extraglandular ducts were surrounded by 
a specialized connective tissue for the mechanical support of the ducts and glands. In study of the collagen fibrils in Glisson's sheath of the liver, Hosoyamada et al. (2000) found that the thickness of collagen fibrils was directly correlated with the caliber of the bile ducts, indicating the correlation between the mechanical stress and thickness of collagen fibrils. The basal lamina, which is mainly composed of collagen type IV, has been shown to have a mechanical function in visceral organs by several authors, including Sakai and Kriz (1987) on the glomerular basement membrane, Mbassa et al. (1988) on the basement membranes of Bowman's capsule, Hijikata and Sakai (1991) on the basement membranes of renal tubules, and Hosoyamada and Sakai $(2005,2007)$ on the basement membranes of the intestinal villi. Thus, it has been well demonstrated that the extracellular fibrillar structures composed of various types of collagens, such as collagen fibrils and basement membranes, have a supportive function in various tissues and organs.

The hitherto accumulated findings indicated the hypothesis that the moderately developed collagen fibrils in the periarterial connective tissue in the kidney have a supportive function around the arteries. In the present study we observed the ultrastructural arrangement of collagen fibrils in the periarterial connective tissue to test the hypothesis of the supportive function of collagen fibrils against arterial pressure in the arterial lumen.

\section{Materials and methods}

In this study, six male Wistar rats weighing 120-140 g (Charles River Japan) were used. All animal experiments were approved by the Ethics Committee of Juntendo University Faculty of Medicine and carried out in compliance with the University's guidelines for animal experimentation. The rats were euthanized by an intraperitoneal injection of sodium pentobarbital $(25 \mathrm{mg} / \mathrm{kg} \mathrm{BW})$.

The rats were perfused with a fixative containing $2.5 \%$ glutaraldehyde in $0.1 \mathrm{M}$ cacodylate buffer, $\mathrm{pH} 7.4$, at $4^{\circ} \mathrm{C}$ via a cannula inserted into the abdominal aorta for about $5 \mathrm{~min}$. After perfusion fixation, the kidneys were dissected out and immersed in $2.5 \%$ glutaraldehyde in the same fixative overnight. The specimens were cut into $250-\mu \mathrm{m}-$ thick slices by a vibratory microtome (DTK-1000, Dosaka EM Co., Ltd., Osaka, Japan) and further processed by the cold dehydration technique described elsewhere (Sakai and Kriz 1987). Briefly, the specimens were immersed in $1.2 \%$ extract of oolong tea (OTE, Suntory Co., Tokyo, Japan) in acetone buffer solution (0.05 M maleate buffer, $\mathrm{pH}$ 6.0, containing $10 \%$ acetone), followed by $1 \%$ uranyl acetate in the same acetone buffer solution, and then dehydrated with a graded series of acetone at 0 to $-30^{\circ} \mathrm{C}$ before embedding in Epon 812. Semithin sections were obtained with a diamond knife, stained with toluidine blue, and observed and photographed under an Olympus AX80T microscope. Ultrathin sections were processed with a diamond knife, stained doubly with uranyl acetate and lead citrate, and observed in a Hitachi H7100 electron microscope.

For SEM preparation, the specimens were transferred through a $25 \%$ aqueous solution of dimethyl sulfoxide (DMSO) into 50\% DMSO, and then freeze-cracked in liquid $\mathrm{N}_{2}$. The cracked specimens were rinsed in $0.1 \mathrm{M}$ phosphate buffer and underwent conductive staining by immersion three times in $1 \%$ osmium tetroxide for $1 \mathrm{~h}$ interposed by $1 \%$ tannic acid for $1 \mathrm{~h}$. The specimens were dehydrated in a graded series of ethanols, substituted with $t$-butyl alcohol, dried at $-20^{\circ} \mathrm{C}$ in a vacuum, and then examined in a Hitachi S-4800 scanning electron microscope (Hitachi, Tokto, Japan) at an accelerating voltage of $5 \mathrm{kV}$.

The caliber of the kidney artery was measured on micrographs at a magnification of $40 \times$. The diameter of collagen fibrils was measured at a magnification of $30,000 \times$ on electron micrographs that included cross-sectional profiles of collagen fibrils using a scale magnifying glass with a magnification of $7 \times$. Measurements were obtained for three groups of cross-sectional profiles of collagen fibrils of each population within a photographic area of $3 \mathrm{~cm}^{2}$ in each section of the artery wall. The magnification of electron micrographs was calibrated with a cross grating replica (Nisshin EM, Tokyo). The area of longitudinal collagen fibrils per arterial perimeter was marked on tracing paper at a magnification of $3,600 \times$ and measured using ImageJ software (National Institutes of Health).

\section{Results}

The periarterial connective tissue of the kidney contained an abundance of collagen fibrils and was obviously different from the peritubular connective tissue, which essentially represented fluid-filled spaces with a paucity of collagen fibrils. When observed with light microscopy, it was easily recognized that the development of periarterial connective tissue was correlated with the size of arteries (Fig. 1). The periarterial connective tissue of large-sized arteries of more than $100-\mu \mathrm{m}$ caliber was so conspicuous that it was easily visible with light microscopy, that of middle-sized arteries of about $70-\mu \mathrm{m}$ caliber was slightly discernible with light microscopy, and that of small-sized arteries of about $20-\mu \mathrm{m}$ caliber could not be identified with light microscopy.

Electron microscopy revealed arrangement of collagen fibrils in the periarterial connective tissue. In the cross- 


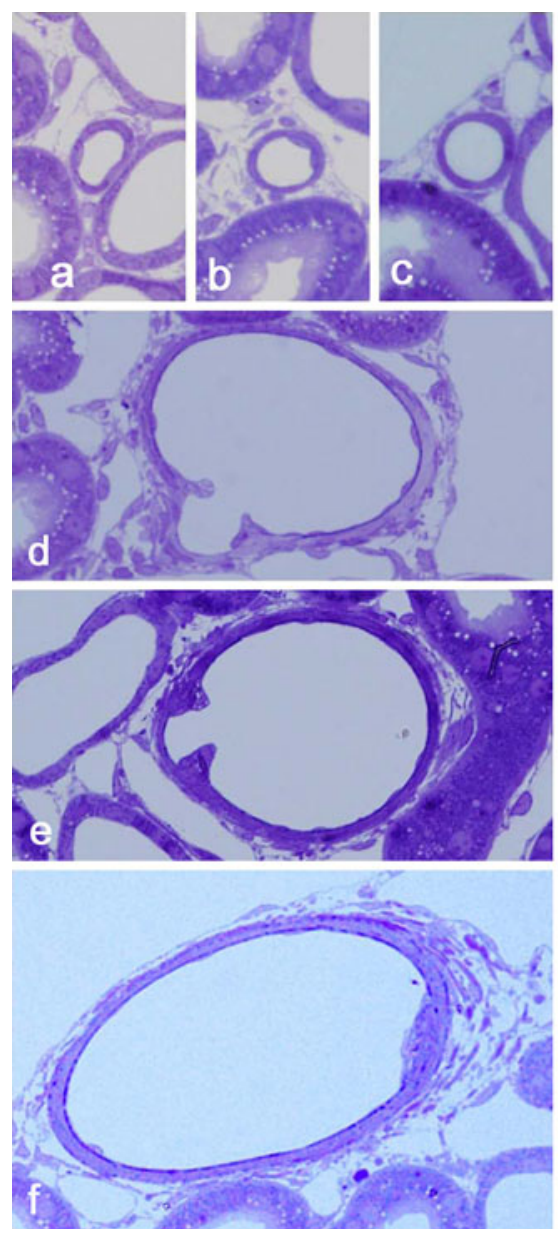

Fig. 1 Light micrographs of the cross-sectional profiles of intrarenal arteries of various sizes in the rat. The collagen bundles of periarterial connective tissue are hardly visible in small arteries of about $20-\mu \mathrm{m}$

section of arteries, the collagen fibrils frequently formed bundles consisting of a few hundred cross-sectional profiles of collagen fibrils, indicating that the collagen bundles were arranged in longitudinal directions (Fig. 2). In middle- and large-sized arteries, the periarterial connective tissue contained an additional small population of collagen bundles with different orientation in regions just outside the smooth muscles. The collagen fibrils of the secondary population appeared as oblique or longitudinal profiles in the cross section of arteries, indicating that they were arranged in circumferential or oblique directions.

From these observations it was concluded that in the small-sized intrarenal arteries, the periarterial connective tissue contained a small amount of longitudinal collagen bundles, and in the middle- and large-sized arteries it contained both a major population of the longitudinal collagen bundles in the outer aspect facing the peritubular interstitium, and a minor population of circumferential or oblique bundles adjacent to the smooth muscles. This conclusion was confirmed by different observations with caliber $(\mathbf{a}-\mathbf{c})$, are moderately developed in middle-sized arteries of about $70-\mu \mathrm{m}$ caliber (d-f), and are well developed in larger arteries of more than $120-\mu \mathrm{m}$ caliber $(\mathbf{g}, \mathbf{h})$. Scale bar $50 \mu \mathrm{m}$

the longitudinal section of arteries and with scanning electron microscopy. In longitudinal sections of arteries, the periarterial connective tissue contained an inner smaller population of collagen fibrils showing cross-sectional profiles and an outer larger population showing longitudinal profiles (Fig. 3). The scanning electron microscopy of freeze-fractured specimens revealed an inner layer of collagen bundles with circumferential or oblique collagen fibrils together with an outer layer of collagen bundles with longitudinally arranged collagen fibrils (Fig. 4). The major outer population of longitudinal collagen bundles and the minor inner population of circumferential or oblique collagen bundles were unequivocally identified with three approaches including cross section, longitudinal section, and scanning electron microscopy of periarterial connective tissue around the middle- or large-sized arteries.

The abundance of collagen fibrils was quantitatively estimated by measuring the area of their profiles in the periarterial connective tissue in the electron micrographs. The area of longitudinal collagen bundles was correlated with the 


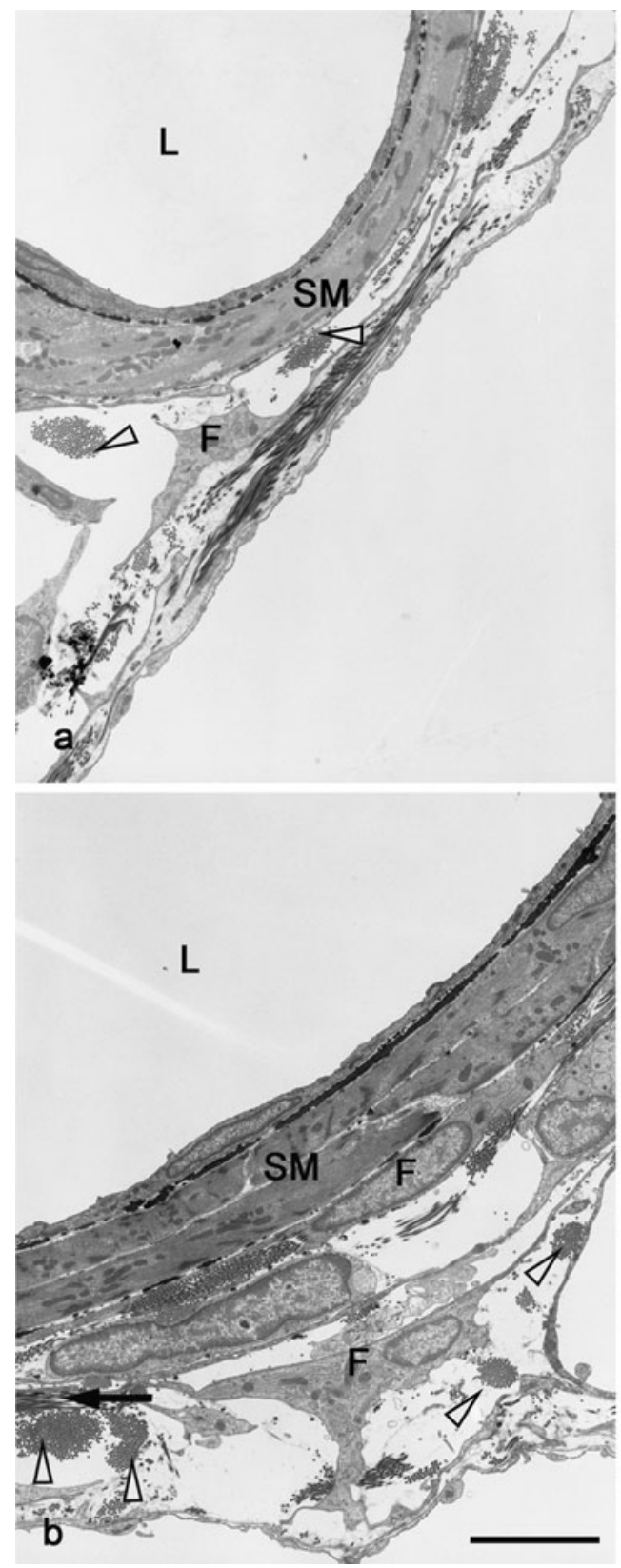

Fig. 2 Electron micrographs of the periarterial connective tissue around the cross-sectional profiles of intrarenal arteries of various sizes in the rat. The arterial profile in a of $20-\mu \mathrm{m}$ caliber represents that in Fig. 1c, that in $\mathbf{b}$ of $75 \mu \mathrm{m}$ represents that in Fig. 1d, that in c of $122-\mu \mathrm{m}$ caliber represents that in Fig. $1 \mathrm{~g}$, and that in $\mathbf{d}$ of $192-\mu \mathrm{m}$ caliber represents that in Fig. $1 \mathrm{~h}$. The cross-sectional profiles of

arterial caliber (Table 1). To estimate the mechanical sustenance of the periarterial connective tissue, we calculated the relative area of longitudinal collagen bundles per arterial perimeter, which was expected to represent the longitudinal wall tension. The relative area of longitudinal collagen bundles differed clearly among three classes of arteries, namely the small- (about 20- $\mu \mathrm{m}$ caliber), middle- (about

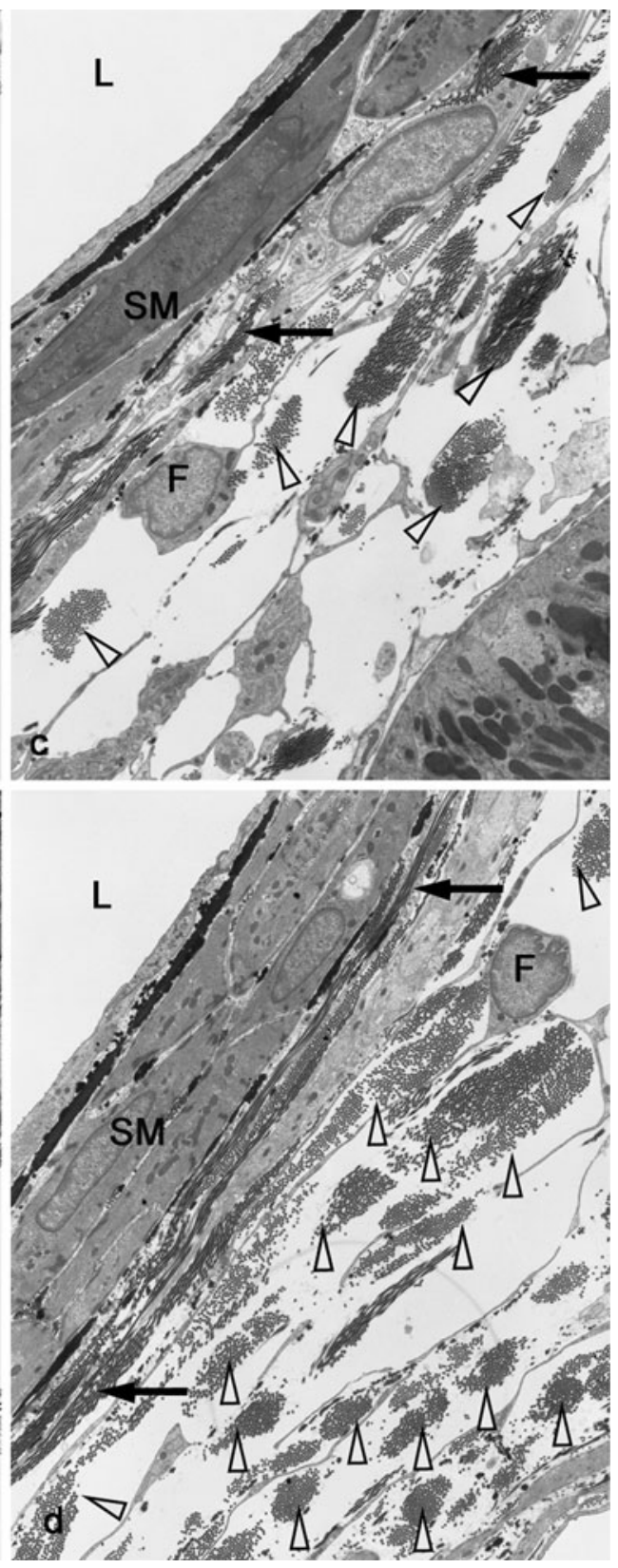

longitudinal collagen bundles (arrowheads) are found scattered among smaller arteries (a), moderately developed in middle-sized arteries (b), and well developed in larger arteries (c, d). In larger arteries, minor populations of circumferential collagen bundles (arrows) are visible as longitudinal sectional profiles in the vicinity of the smooth muscles. Scale bar $5 \mu \mathrm{m}$

$70-\mu \mathrm{m}$ caliber), and large-sized arteries (larger than $100-\mu \mathrm{m}$ caliber). The expected longitudinal wall tension developed by the collagen fibrils was dependent on the arterial caliber, assuming that the area of collagen bundles was proportional to the wall tension.

The collagen fibrils were photographed in periarterial connective tissue of arteries with different calibers in 


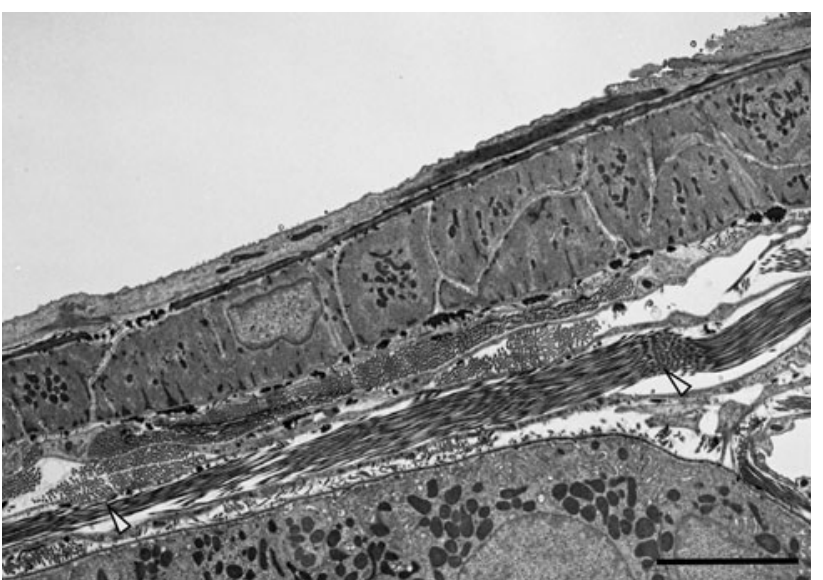

Fig. 3 Electron micrograph of the periarterial connective tissue around the longitudinal sectional profile of a $33-\mu \mathrm{m}$-caliber intrarenal artery in the rat. The longitudinal collagen fibrils are found as longitudinal sectional profiles (arrowheads), whereas the population of circumferential collagen fibrils is visible as cross-sectional profiles in the vicinity of the smooth muscles. Scale bar $5 \mu \mathrm{m}$

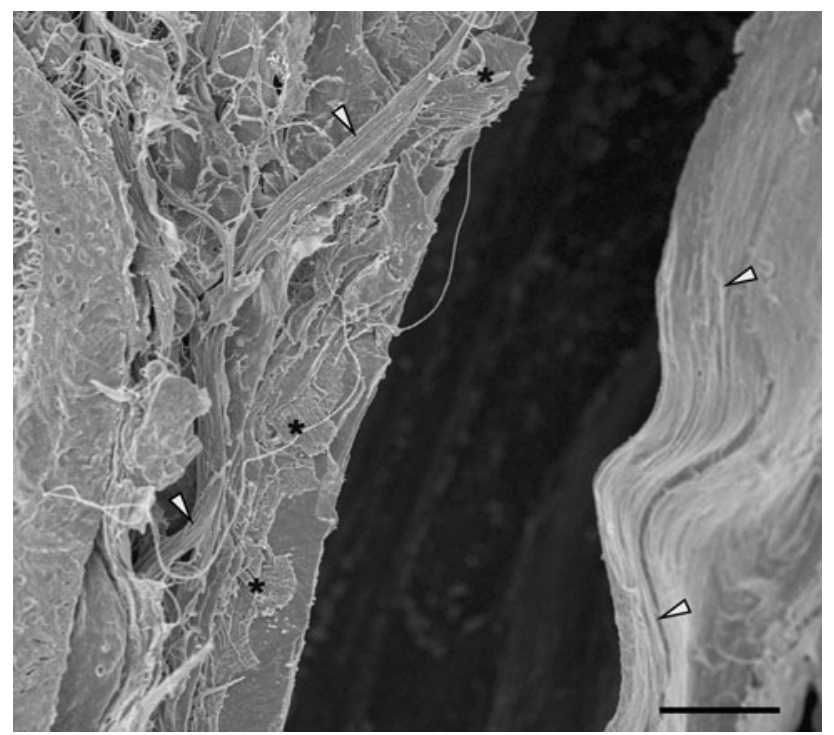

Fig. 4 Scanning electron micrograph of the periarterial connective tissue around the intrarenal artery in the rat running in an almost vertical direction in the figure. The wavy appearance of the longitudinal collagen bundles (arrowheads) is obviously seen in the outer layer that covers the circumferential collagen bundles in the inner layer (asterisks). The profiles of endothelial cells are visible beyond the dark vascular lumen. Scale bar $5 \mu \mathrm{m}$

electron micrographs to measure the caliber of individual collagen fibrils (Fig. 5). The caliber of the collagen fibrils was different among arteries, and obviously proportional to the arterial caliber in the graph representing the relationship between the caliber of collagen fibrils and the arterial caliber (Fig. 6). The regression line is represented by the equation $y=0.143 x+44.56(r=0.819)$.
Table 1 The area of longitudinal collagen bundles per arterial perimeter around intrarenal arteries of various sizes in the rat kidney

\begin{tabular}{ll}
\hline $\begin{array}{l}\text { Diameter } \\
(\mu \mathrm{m})\end{array}$ & $\begin{array}{l}\text { Area of } \\
\text { longitudinal } \\
\text { collagen fibrils per } \\
\text { arterial perimeter } \\
\left(\times 10^{-3} \mu \mathrm{m}^{2} / \mu \mathrm{m}\right)\end{array}$ \\
\hline 12 & 0.74 \\
17.5 & 0.01 \\
20 & 0.46 \\
71.8 & 1.82 \\
75.2 & 2.88 \\
76.8 & 2.58 \\
121.9 & 10.44 \\
192.1 & 8.70 \\
\hline
\end{tabular}

\section{Discussion}

This study revealed the structural characteristics and heterogeneity of collagen bundles in the periarterial connective tissue in the rat kidney. First, the collagen bundles consisted of two populations including major longitudinal bundles found in the outer portion and minor circumferential bundles occupying the inner portion. Second, the amount of collagen bundles was remarkably correlated with the arterial caliber. Third, the thickness of individual collagen fibrils was slightly correlated with the arterial caliber.

These structural characteristics of the collagen bundles in the periarterial connective tissue fit well with the hypothesis that they develop wall tension to stabilize the arterial wall against the hydrostatic pressure in the arterial lumen. The wall tension contains two components including a circumferential tension $\left(T_{\mathrm{C}}\right)$ and a longitudinal tension $\left(T_{\mathrm{L}}\right)$. They are represented by the equation, $T_{\mathrm{C}}=r \times \Delta P$, and $T_{\mathrm{L}}=r \times \Delta P / 2$, where $r$ is the radius of the artery and the $\Delta P$ is the transmural pressure difference (Sakai and Kobayashi 1992). These equations indicate that $T_{\mathrm{C}}$ is twice as large as $T_{\mathrm{L}}$, and that both $T_{\mathrm{C}}$ and $T_{\mathrm{L}}$ are positively correlated with the arterial caliber. In the arterial wall the smooth muscle cells are arranged in the circumferential direction in the media, so that they would develop $T_{\mathrm{C}}$ and not $T_{\mathrm{L}}$. The longitudinal tension may be developed by the other structures such as the longitudinal stress fibers in the endothelial cells, elastic fibers in the inner and outer elastic laminae, and the collagen fibrils in the periarterial connective tissue. Considering the paucity of endothelial stress fibers and elastic lamina in the renal arteries, the longitudinal tension is thought to be developed mainly by the collagen fibrils. This argument is supported by the observations that the longitudinal collagen bundles in the periarterial connective tissue far exceed the circumferential collagen bundles in amount.

Since the wall tension is positively correlated with the arterial caliber, the periarterial connective tissue of larger 
Fig. 5 High power view of the cross-sectional profiles of collagen fibrils in the periarterial connective tissue around the cross-sectional profiles of intrarenal arteries of various sizes. The artery calibers are $28 \mu \mathrm{m}(\mathbf{a}), 70 \mu \mathrm{m}$ (b), $72 \mu \mathrm{m}$ (c), $75 \mu \mathrm{m}$ (d), $77 \mu \mathrm{m}$ (e), $100 \mu \mathrm{m}$ (f), $122 \mu \mathrm{m}$ (g), $125 \mu \mathrm{m}(\mathbf{h}), 192 \mu \mathrm{m}(\mathbf{i})$, and $200 \mu \mathrm{m}(\mathbf{j})$, respectively. The caliber of collagen fibrils appears to be correlated with the caliber of arteries. Scale bar $0.5 \mu \mathrm{m}$
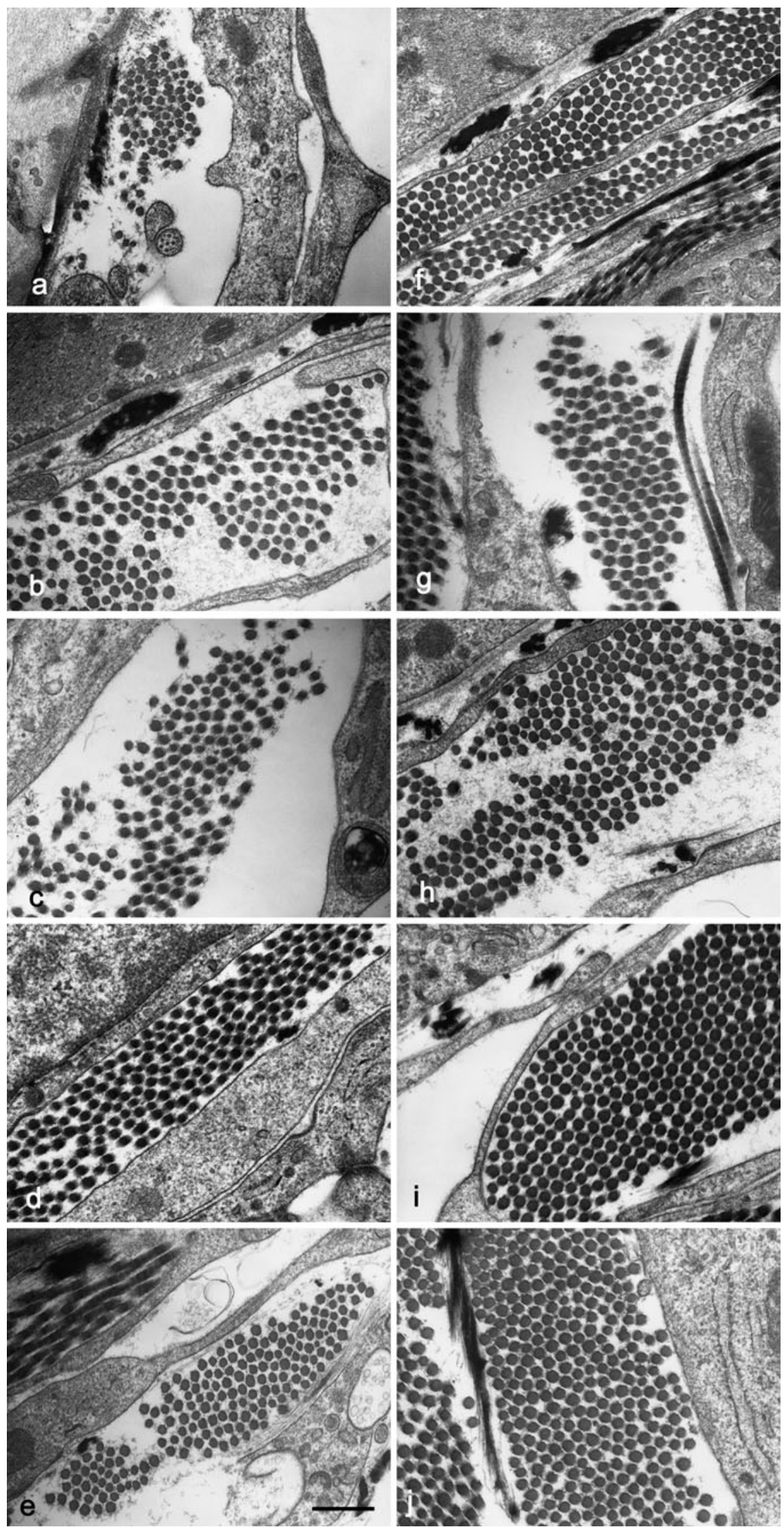


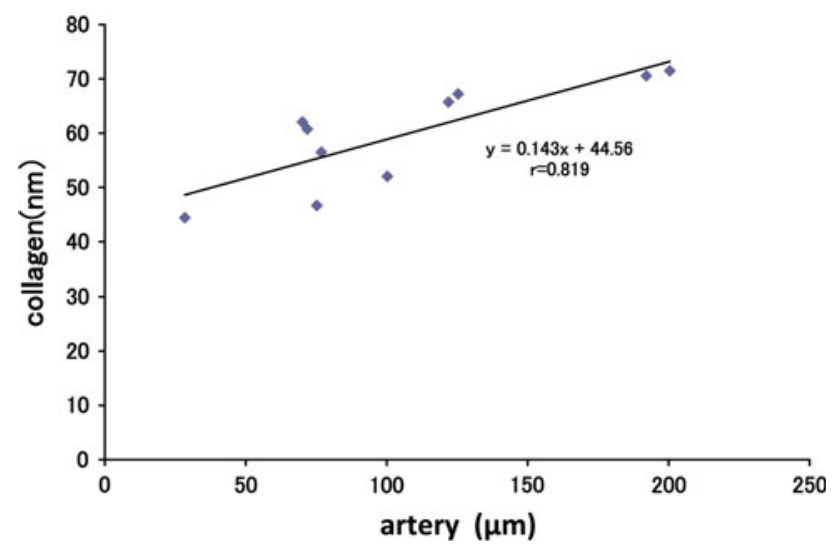

Fig. 6 Relationship between the caliber of collagen fibrils and the arterial caliber in the rat kidney. The regression line is represented by the equation $y=0.143 x+44.56(r=0.819)$

arteries should develop larger wall tension. This argument is supported by the observation that the amount of collagen bundles in the periarterial connective tissue is correlated with the arterial caliber. The present study revealed that in the larger arteries, the larger amount of collagen bundles in the periarterial connective tissue serves to develop more wall tension to counterbalance the transmural hydraulic pressure difference.

It has been frequently reported that the diameter of individual collagen fibrils is variable and possibly correlated with the mechanical stress acting on the tissue. Perry et al. (1978) pointed out that the diameter of fibrils and tensile strength of the tissue are correlated in several types of tissues. Matthew and Moore (1991) compared the diameter distribution of fibrils in healing tissue after complete and partial transection, and suggested that the different diameters can be explained by different levels of mechanical stress. Hosoyamada et al. (2000) suggested a correlation between the increase in fibril diameter along the bile ducts and an increase in mechanical stress acting on Glisson's sheath. A similar increase in fibril diameter along the renal arteries was observed in the present study, but the tendency in the periarterial connective tissue $(0.143)$ is much smaller compared with those in Glisson's sheath (0.357 and 0.445). This fact suggests that the mechanical stress acting on the individual collagen fibrils in the periarterial connective tissue increases in proportion to the arterial caliber, but the increment of stress is smaller than in the case of Glisson's sheath. The difference may be explained by the increased amount of collagen fibrils in larger arteries, which decreases the mechanical stress acting on the individual collagen fibrils.

From the observations on the periarterial connective tissue, we concluded that the collagen fibrils in the periarterial connective tissue are arranged to develop wall tension in the longitudinal direction to counterbalance the transmural hydraulic pressure difference, whereas the circumferential tension is developed by the smooth muscle cells in the media. The different functions of the smooth muscle cells and collagen fibrils in supporting the arterial structure against the transmural pressure gradient appear to be unique in the intrarenal arteries, which is not allowed to distend in the longitudinal direction because of the constant volume of the renal parenchyma bordered by a rigid capsule (Kriz and Kaissling 1985). In other tissues, the longitudinal tension may be developed by smooth muscle cells as reported by Rhodin (1967) who revealed in the arteries of muscular fascia that a part of the smooth muscle cells are arranged in an oblique direction to develop both circumferential and longitudinal tensions.

Acknowledgments This study was partially supported by a High Technology Research Center Grant from the Ministry of Education, Culture,Sports, Science and Technology of Japan. We thank Mr. Mitsutaka Yoshida of the Central Laboratory of Medical Science, Division of Ultrastructural Research, Juntendo University, for his skillful technical assistance in electron microscopy.

Conflict of interest No benefits in any form have been received or will be received from a commercial party related directly or indirectly to the subject of this article.

Open Access This article is distributed under the terms of the Creative Commons Attribution Noncommercial License which permits any noncommercial use, distribution, and reproduction in any medium, provided the original author(s) and source are credited.

\section{References}

Barajas L, Wang P (1975) Localization of tritiated norepinephrine in the renal arteriolar nerves. Anat Rec 195:525-534

Hijikata T, Sakai T (1991) Structural heterogeneity of the basement membrane in the rat proximal tubule. Cell Tissue Res 266:11-22

Hosoyamada Y, Sakai T (2003) The ultrastructure of periductal connective tissue and distinctive populations of collagen fibrils associated with ductal epithelia of exocrine glands. Arch Histol Cytol 66:407-418

Hosoyamada Y, Sakai T (2005) Structural and mechanical architecture of the intestinal villi and crypts in the rat intestine: integrative reevaluation from ultrastructural analysis. Anat Embryol 210: $1-12$

Hosoyamada Y, Sakai T (2007) Mechanical components of rat intestinal villi as revealed by ultrastructural analysis with special reference to the axial smooth muscle cells in the villi. Arch Histol Cytol 70:107-116

Hosoyamada Y, Kurihara H, Sakai T (2000) Ultrastructural localisation and size distribution of collagen fibrils in Glisson's sheath of rat liver: implications for mechanical environment and possible producing cells. J Anat 196:327-340

Kriz W, Dieterich HJ (1970) Das Lymphgefässsystem der Niere bei einigen Säugetieren. Licht- und elektronenmikroskopische Untersuchungen. Z Anat Entwicklungsgesch 131:111-147

Kriz W, Kaissling B (1985) Structural organization of the mammalian kidney. In: Seldin DW, Giebisch G (eds) The kidney: physiology and pathophysiology. Raven Press, New York 
Lemley KV, Kriz W (1991) Anatomy of the renal interstitium. Kidney Int 39:370-381

Lorber M (1989) Elastic fibers in the rat exorbital lacrimal gland duct system. Invest Ophthalmol Vis Sci 30:2002-2011

Lorber M (1991) Branchings and course of the larger ducts and accompanying structures within the rat submandibular salivary gland. Am J Anat 190:133-156

Lorber M (1992) Elastic fibers in the duct system of the rat submandibular salivary gland. Anat Rec 234:335-347

Lorber M (1993) Regional differences within the external duct of the rat exorbital lacrimal gland. Exp Eye Res 56:471-480

Matthew CA, Moore MJ (1991) Collagen fibril morphometry in transected rat extensor tendons. J Anat 175:263-268

Mbassa G, Elger M, Kriz W (1988) The ultrastructural organization of the basement membrane of Bowman's capsule in the rat renal corpuscle. Cell Tissue Res 253:151-163
Perry DA, Barnes GR, Craig AS (1978) A comparison of the size distribution of collagen fibrils in connective tissues as a function of age and a possible relation between fibrils size distribution and mechanical properties. Proc R Soc Lond B Biol Sci 203: 305-321

Rhodin JA (1967) The ultrastructure of mammalian arterioles and precapillary sphincters. J Ultrastruct Res 18:181-223

Sakai T, Kobayashi N (1992) Structural relationships between the endothelial actin system and the underlying elastic layer in the distal interlobular artery of the rat kidney. Anat Embryol (Berl) 186:467-476

Sakai T, Kriz W (1987) The structural relationship between mesangial cells and basement membrane of the renal glomerulus. Anat Embryol (Berl) 176:373-386 